NBER WORKING PAPER SERIES

SHOULD PRIVATE PENSIONS BE INDEXED?

Martin Feldstein

Working Paper No. 787

NATIONAL BUREAU OF ECONOMIC RESEARCH 1050 Massachusetts Avenue

Cambridge MA 02138

October 1981

The research reported here is part of the NBER's project on

Pensions. Any opinions expressed are those of the author and not those of the National Bureau of Economic Research. 
The analysis in this paper was motivated by the apparent puzzle that, despite substantial uncertainty about future inflation rates, private pensions are almost universally unindexed. Moreover, although a variable annuity invested in short-term money market instruments provides a good inflation hedge, almost all private pensions provide a fixed annuity.

The results of the analysis indicate that the existence of unindexed pensions and fixed annuities is not at all surprising. Even without Social Security, it may be optimal to have a completely unindexed private pension and it is generally not optimal to have a completely indexed pension.

The availability of an optimal (or greater than optimal) amount of Social Security generally reduces the desired degree of indexing and, under a variety of conditions, makes it optimal to have no indexing at all in the private pension.

Because unexpected changes in the price level do not alter the value of Social Security pensions, the existence of inflation uncertainty makes a Social Security pension optimal when it would not otherwise be and an increase in inflation uncertainty is likely to increase the optimal reliance on Social Security. But despite these conclusions, the analysis shows that including some Social Security in an overall pension program is necessarily optimal only when both money market instruments and Social Security have rates of return that are known with certainty. When the real yield on money market instruments is uncertain, the optinal pension arrangement may be a partially indexed private pension even though Social Security is risk-free and has a return that is higher than the expected rate on the money market instruments. Similarly, when Social Security is risky, the optimal arrangement may be to exclude Social security and to use a partially indexed private pension. In all cases, an individual who has a low enough degree of risk aversion will prefer no Social Security and a completely unindexed private pension.

Martin Feldstein

National Bureau of Economic Research 1050 Massachusetts Avenue Cambridge, Massachusetts 02138 


\section{Should Private Pensions be Indexed?}

Martin Feldstein*

In recent years, the rapid and unexpected increases in the price level have significantly eroded the value of retirees' private pension benefits. An employee who retired in 1970 with a pension equal to 50 percent of the average manufacturing wage received a monthly check for $\$ 289$. The 113 percent increase in the level of consumer prices in the subsequent decade reduced the real value of that pension benefit by 53 percent to only 24 percent of the average 1970 manufacturing wage. Although some firms have voluntarily increased retirees' benefits, these adjustments have almost always been far less than the rise in the price level.

Since retirees obviously care about their real incomes, it is a puzzle that, after more than a decade of rapid inflation, private pensions are still fixed in nominal terms. Why have employers and employees until now not negotiated pension benefits that are indexed or partly indexed to the price level? Alternatively, why have employee pensions not taken the form of variable annuities based on floating rate instruments whose nominal yield varies in the short-run with the rate of inflation (Bodie, 1980a,b) ? ${ }^{1}$ Does current behavior represent a mistake by employees and unions that makes it appropriate

\footnotetext{
Professor of Economics, Harvard University, and President, National Bureau of Economic Research. This paper is part of the NBER Study of Public and Private Pensions. I am grateful to participants in the study for comments on an earlier version of this paper.

1 The key issue is the employee's risk of uncertain inflation. It would not really be indexing if, instead of a constant nominal annual benefit, the benefit rises at a rate that is fixed at the time of retirement. Although the increase in benefits might be related to the expected rate of inflation, the employee would continue to bear the entire risk of unexpected changes in inflation. I shall reserve the term "indexing" for mechanisms that reduce the uncertainty of real benefits by linking benefits either to the price level or to the yield on short-term money market instruments.
}

081981-A 
in some sense to modify the laws governing pensions to require such indexing?

The present paper shows that the existing arrangement with purely nominal private pensions may in fact be optimal in the presence of the indexed system of Social Security retirement pensions. Of course, since an individual who relies on a nominal pension is in effect making a risky investment, there will be unexpected losses and gains. The recent losses by retirees should be seen as just such an unfortunate ex post outcome and not as an indication that private pensions are either incompatible with inflation or should be indexed. Because protection against inflation risk can only be obtained at the cost of accepting a lower expected rate of return, ${ }^{l}$ the potential retiree will generally choose to be less than fully protected against inflation, i.e., will choose a partially indexed pension. Moreover, Social Security retirement benefits provide a fully indexed pension that replaces a substantial fraction of previous peak earnings for most current retirees. 2 The combination of Social Security and a private pension thus provides a total pension arrangement that is substantially indexed even if the private pension is fixed in nominal terms. For most

1 Pesando (1981) discusses a very different sense in which it is expensive to maintain the real value of pension benefits: keeping the same initial pension benefit and then raising benefits in proportion to the price level clearly increases the expected value of benefits in all subsequent years. My emphasis is on reducing the variance around any expected real stream of benefits. A lower real variance requires investing in assets with a lower expected return and thus increases the cost (i.e., the initial value of assets) required to provide any expected stream of real benefits.

2 An employee who has had median earnings for all of his working life now retires at age 65 with a Social Security pension that replaces more than 40 percent of his peak pretax earnings. If he is married and his wife does not claim benefits on the basis of her own income, his benefit will be increased to more than 60 percent of his peak pretax earnings. Since these benefits are not subject to income or payroll tax, they replace more than 75 percent of after tax earnings. Since Social Security is indexed by the Consumer Price Index, it is probably overindexed with respect to a true variable-weight measure of retirees' cost of living. 
employees, the extent of indexing in the combined pension may be such that no indexing of the private pension would be desired.l

The analysis in this paper makes these ideas more precise and proves specific conclusions. Although the models employed are clearly a simplification of reality, I believe that they capture the essential features of the problem. The first section of the paper analyzes an economy without Social Security in which all retirement consumption is financed by a private pension. In section 2, Social Security is introduced and the analysis examines the optimal mix of Social Security and private pensions as well as the optimal indexing of private pensions. The third section extends this analysis to a Social Security program with uncertain benefits. 2 There is then a brief concluding section.

\section{Optimal Pension Indexing without Social Security}

The simplest framework within which to analyze the problem of pension indexing is a two-period two-asset model. Employees work in the first period and contribute an amount $\mathrm{C}$ to a retirement pension. In the second period of their life, employees are retired and then receive a pension with real (but generally uncertain) value $P$.

1 For employees with very high earnings, Social security benefits are low relative to private pension benefits and the degree of overall indexing of the combined pension is therefore correspondingly low. Although such employees may prefer to have some indexing of their pension benefits, the legal rules for tax deductible ("qualified") pensions presumably prevents "discriminating" among different classes of employees. Moreover, high income employees tend to have additional portfolio assets and liabilities with which to achieve the overall desired degree of indexing (although generally with less favorable tax treatment). For some lower wage employees the opposite is true; the combined pension provides too much indexing. I return to these below.

$2 \mathrm{All}$ of the analysis ignores other forms of individual wealth. The vast majority of retirees depend almost completely on the combination of social security and other pension income. Additional assets generally consist of only an owner-occupied home and a small amount of liquid precautionary balances. 
In a "defined contribution" type of pension plan, employees invest

their pension contributions in a portfolio of bonds and corporate stock. When they retire, they receive an annuity based on the value of these assets. Since the value of bonds and their interest payments are fixed in nominal terms, the real rate of return of the bond portion varies inversely with changes in both the price level and the rate of inflation. Although the real value of corporate stock should be unaffected by changes in the price level, changes in the expected rate of inflation do cause changes in real share values. 1 Thus the real value of a defined contribution pension invested in any combination of bonds and stocks is uncertain.

In the more common "defined benefit" type of pension, the employer invests the contributions and promises the employee benefits that depend on the employee's final year's earnings and that then remain fixed in nominal terms. ${ }^{2}$ In the simplest interpretation of the defined benefit plan, the retired employee has a fixed nominal annuity that is analogous to a bond. Because the firm can invest the pension funds in a $\mathrm{mix}$ of bonds that exactly matches the benefit obligation, the firm provides this bond yield to the retiree. Although firms may in fact invest pension assets in a mix of stocks and bonds, the equity owners of the firm receive the excess return (if any) generated in this way in exchange for accepting the extra risk of a non-hedged investment.

More generally, however, the employee in a defined benefit plan may receive benefits that depend on the performance of the pension fund. This is

1 See, e.g., Feldstein (1980a, 1980b), Hendershott and th (1979) and Summers (1981a).

2 The nature of the obligation and of the investment is actually more cormplicated in practice. The employer is technically only obligated to provide for the "vested" benefits that are based on existing service. But to prevent a rapid increase in pension costs as employees approach retirement, employers often anticipate future expected pension obligations. Some firms, however, do not fully fund even their vested obligations but substitute an implicit corporate pronise. See Feldstein (1981). 
true not only because a low enough value of fund assets can reduce benefits below the promised level but also because successful pension performance can lead to increases in the promised level of benefits and ad hoc "voluntary" increases in benefits to retirees. ${ }^{1}$ In what follows, I do not distinguish between defined benefit and defined contribution plans.

Although virtually all private pensions are unindexed, this is not necessary. Zvi Bodie $(1980 a, b)$ has recently shown that assets invested in a sequence of three-month Treasury bills provide a very good inflation hedge. ${ }^{2}$ Thus, individuals in a defined contribution plan can achieve an essentially risk-free real return by investing in bills and an employer who manages a defined benefit plan can offer an essentially indexed pension without additional risk to shareholders by investing in such bills.

I shall denote the real return on bills as the random variable $r_{b}$ with mean $\mu_{b}$ and variance $\sigma_{b b}^{2}$. If this type of investment provides a perfect index asset, there is no correlation between $r_{b}$ and the inflation rate. In some of the analysis that follows, I shall make the stronger assumption that $r_{b}$ is a constant $\left(\sigma_{\mathrm{bb}}^{2}=0\right)$. Bodie's empirical analysis showed that the return on the

1 See Bulow (1981), Miller and Scholes (1981) and Pesando (1981) on the beneficial interest of employees in the pension fund.

2 More specifically, Bodie showed that to minimize the variance of the real return on assets, i.e., to come as close as possible to a risk-free priceindexed investment, the assets should be invested in Treasury bills since their nominal yield varies directly with inflation. Although the close correlation of the nominal yield on bills and inflation has characterized the past two decades, the same relation did not hold in earlier years (Summers, 1981; Mishkin, 1981); in Bodie's defense, however, it may reasonably be argued that the Federal Res erve Policy in the decade before 1953 makes this period irrelevant and that the next decade was one of such price stability that nothing can reasonably be inferred about the relation between inflation and short-term interest rates. Bodie shows also that the historical variance may be slightly reduced by including commodity futures as well. Bodie's optimum assumes that short sales by pensions are not permitted. 
minimum-real-variance portfolio has averaged approximately zero (i.e., $\mu_{b}=0$ ). and the annual standard deviation was approximately one percentage point $\left(\sigma_{\mathrm{bb}}=0.01\right)$. In the important special case of $\mu_{b}=\sigma_{b b}^{2}=0$, "bills" are a perfect real store of value and investment in bills provides an indexed pension.

Similarly, I shall denote the real yield on the completely unindexed pension by the random variable $r_{u}$ with mean $u_{u}$ and variance $\sigma_{u u}^{2}$. This yield can be interpreted as the yield that is implicit in setting the level of the nominal annuity of a strict defined benefit plan, or as the ex post yield on the mix of debt and equity in a defined contribution plan, or as the ex post yield on a performance-related defined benefit plan.

The real value of the employee's pension in retirement is given by

$$
P=U\left(I+r_{u}\right)+(C-U)\left(I+r_{b}\right)
$$

where $C$ is the pension contribution, $U$ is the amount of the contribution that purchases an unindexed pension (of either the defined contribution or defined benefit type) and $\mathrm{C}-\mathrm{U}$ is the "indexed" portion represented by an investment in bills. The employee's problem in designing a pension is thus similar to a portfolio allocation problem, i.e., selecting the value of $U$ that maximizes the employee's expected utility of retirement consumption $E[V(P)]$ subject to the constraint implied by equation 1.1.1 I shall assume throughout the analysis that short-sales of either asset are not permitted; thus, $C \geqslant U \geqslant 0$.

1 In principle, the employee decides the size of the pension contribution and the form of investment simultaneously. The present analysis takes the size of contribution as given. 
If the returns $\left(r_{u}\right.$ and $r_{b}$ ) are normally distributed (or if the individual's utility function can be approximated by a quadratic function), the individual's preferences can be represented graphically by a set of indifference curves in terms of the mean and standard deviation of the portfolio's terminal value (Tobin, 1958). Figure 1 combines these indifference curves with the opportunity locus in the important case in which investment in "bills" provides a fully indexed pension with zero mean return.

Consider first the line connecting the origin with point $\bar{U}$. The origin represents a pension fund invested exclusively in bills (and is therefore marked with the letter $\bar{b}$ ). Since there is no uncertainty about the real return on these assets, the standard deviation of the pension benefit is zero. The pension benefit is therefore $C$, the initial contribution. Point $\bar{U}$ represents the pension that results when the pension is completely unindexed. Since the standard deviation of the return per dollar contributed to the unindexed pension is $\sigma_{\mathrm{uu}}$, the standard deviation of the pension benefit is $\bar{U} \sigma_{u u}$. Equation 1.1 implies that, for any $U$, the expected pension benefit is $E(P)=C-U+U\left(1+\mu_{L}\right)=$ $\mathrm{C}+\mathrm{U}_{\mathrm{L}} \cdot$ The expected benefit associated with the completely unindexed pension is thus $\mathrm{C}+\bar{U}_{\mu_{\mathrm{u}}}$. Any point on the straight line between the origin and $\bar{U}$ represents a feasible pension allocation.

The indifference curve tangent to the $\overline{b U}$ line at E represents preferences that lead to a partially indexed pension; any move toward more complete indexing causes a reduction in expected pension benefits that outweighs the reduction in risk.

Different preferences would lead to different degrees of pension indexing. A reduction in risk aversion implies flatter indifference curves 
Figure 1

Optimal Pension Indexing when Bills are Riskless

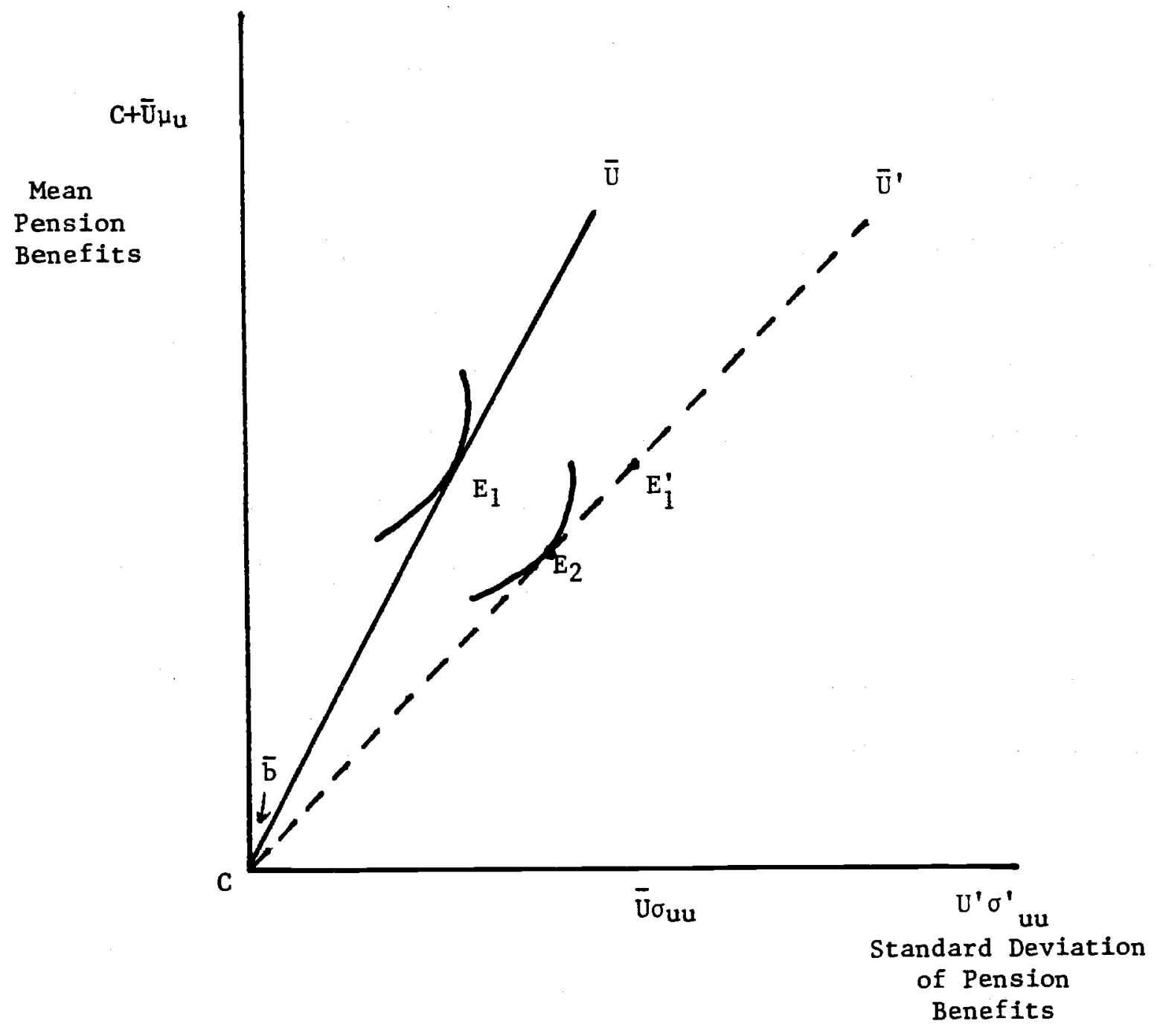


(i.e., more nearly parallel to the horizontal axis) and can imply no tangency along the $\bar{b} \bar{U}$ line. In this case, the optimal pension will correspond to point $\bar{U}$ with no indexing at all. 1 Increases in risk aversion shifts the optimum to a more fully indexed pension but, except for the case of "infinitely" risk averse individuals, the optimum will not involve a fully indexed pension. 2 Thus the optimal pension will not be fully indexed and may be either partially indexed or not indexed at all.

To make these ideas more precise, consider an individual whose preferences can be represented by a constant absolute risk aversion utility function, $V(P)=-\frac{1}{\alpha}^{-\alpha P}$ with risk aversion paramenter $\alpha>0$ (Arrow, 1971). Since the amount of the pension contribution that is unindexed is $U$, the value of the pension is the random amount $\mathrm{P}=\mathrm{C}+\mathrm{r}_{\mathrm{u}} \mathrm{U}$. Thus,

$$
\begin{aligned}
E[V(P)] & =E\left[-\frac{1}{\alpha} e^{-\alpha P}\right] \\
& =E\left[-\frac{1}{\alpha} e^{-\alpha\left(C+r_{u} U\right)}\right]
\end{aligned}
$$

and, if the return $r_{u}$ is normally distributed,

$$
E[V(P)]=-\frac{1}{\alpha} e^{-\alpha-\alpha \mu_{u}+\frac{1}{2} \alpha^{2} U^{2} \sigma^{2} u u}
$$

Maximizing $E[V(P)]$ with respect to $U$ implies the optimal unindexed share of the pension is

1 If pensions could sell bills short and invest in bonds, the true optimum would be on the extension of line $\overline{\mathrm{bU}}$ with greater yield and greater risk.

2 Intuitively, an individual who has assumed no risk will always be willing to accept a small amount of risk in order to raise the mean return. 


$$
U^{*}=\frac{\mu_{u}}{\alpha \sigma^{2} u u} \text {. }
$$

For any finite value of the risk aversion parameter, $U^{*}>0$ and the pension is less than completely indexed. Moreover, if the risk aversion and the variance are low enough relative to the expected return, the entire pension fund will be unindexed $\left(U^{*} \geq C\right) .1$

Returning to figure 1, we can consider the effect of an increase in inflation uncertainty on the optimal extent of pension indexing. An increase in inflation uncertainty (on the assumption that bills permit complete indexing) is equivalent to an increase in the variance of the unindexed pension and therefore a shift in locus of feasible pensions from $\bar{b} \bar{U}$ to $\bar{b} \bar{U}^{\prime}$. At every point along $\bar{b} \bar{U}^{\prime}$ the tradeoff between risk and return is less favorable; a greater increase in real risk must be accepted for each increase in expected real return. Moreover, at the degree of indexing that was optimal with the lower level of inflation uncertainty (i.e., at point $E^{\prime}$ on $\bar{b} \bar{U}$ ' that corresponds to point $E$ on $\overline{b U}$ ), the individual has the same expected return but more risk. It seems likely therefore that with more initial risk and a less favorable risk-return tradeoff, the individual would choose to index the pension more completely. This is shown in figure 1 where the new optimu at $E_{2}$ lies closer than $E^{\prime}$ to the complete indexing point. In the constant absolute risk aversion case of equation 1.4 it is also clear that an increase in $\sigma_{u u}^{2}$ causes $U^{*}$ to fall and the optimal degree of indexing to rise. ${ }^{2}$

1 Note that a result like 1.4 can be obtained with constant proportional risk aversion in continuous time models; see Bodie (I979).

2 It is of course possible that an increase in inflation uncertainty could reduce the degree of indexing, i.e., that the indifference curve would be tangent to $\overrightarrow{b U}^{\prime}$ at a point between $E^{\prime}$, and $\bar{U}^{\prime}$. This would imply that risk aversion decreased as risk increased for given yield, surely an unlikely preference. 
This shift in the degree of pension indexing shows two of the adverse consequences associated with an increase in inflation uncertainty. First, in order to reduce the added risk, individuals shift their pensions to a more completely indexed form with lower expected yield. Second, even with a greater degree of indexing, the individual may have a greater risk (as shown in figure 1). The lower indifference curve at $\mathrm{E}_{2}$ reflects both of these adverse consequences. The analysis based on figure 1 and equation 1.2 assumed the possibility of a perfectly indexed pension that provides a perfect store of value but no real return. ${ }^{1}$ More generally, a pension based on a variable annuity invested in money market instruments ("bills") would provide a random return with mean $\mu_{b}$, variance $\sigma_{b b}^{2}$ and covariance $\sigma_{b b}^{2}$ with the return on an unindexed pension fund. With $r_{b}$ uncertain, it follows from equation 1.1 that the variance of the pension value is $(C-U)^{2} \sigma_{b b}^{2}+U^{2} \sigma_{u u}^{2}+2 U(C-U) \sigma_{u b}^{2}$. The minimum variance does not correspond to a pension invested only in bills but to one in which the unindexed fraction is

$$
\frac{\hat{U}}{\mathrm{C}}=\frac{\sigma_{\mathrm{bb}}^{2}-\sigma_{\mathrm{ub}}^{2}}{\sigma_{\mathrm{bb}}^{2}+\sigma_{\mathrm{u} u}^{2}-2 \sigma_{\mathrm{ub}}^{2}} .
$$

The real returns on an unindexed pension and on bills may be correlated either positively or negatively. If the correlation is negative

1 Since a perfect index asset does not exist, such a perfect index pension would have to be a real liability of the corporation and its shareholders. For accepting such risk, shareholders would have to be compensated and the return to erployees might therefore be negative. The analysis based on figure 1 and equation 1.2 can be interpreted as an approximation to either the opportunity that shareholders offer to employees or the opportunity made available by the market. 
(e.g., because a higher real short-term interest rate is associated with a higher nominal long rate and therefore with a fall in bond prices or in the real value of a fixed nominal annuity) $\sigma^{2} u b<0$ and $\hat{U}$ is between zero and $C$, implying that the minimum variance pension is only partially indexed. This case is shown by the $\overrightarrow{\mathrm{bU}}$ curve in figure 2 ; the point marked $\hat{U}$ indicat es the minimum variance $\operatorname{mix}$.

Even if the correlation between the real yields on bills and on an unindexed pension is positive, the minimum variance pension is only partly indexed if $\sigma^{2} \mathrm{ub}<\sigma_{\mathrm{bb}}^{2}$, i.e., if the regression coefficient of the return on the unindexed pension on the return on bills is less than one. When this is not true, i.e., when $\sigma_{u b}^{2}>\sigma_{b b}^{2}$, the minimum variance pension is invested in bills only. ${ }^{1}$ If $\sigma^{2} \mathrm{ub}=\sigma_{\mathrm{bb}}$, the investment opportunity locus looks like bU' in figure 2 with the minimum variance at point $\bar{b}$. If, however, $\sigma^{2} \mathrm{ub}>\sigma_{\mathrm{bb}}^{2}$, the investment opportunity locus looks like $\bar{b} \bar{U} "$ in figure 2 with an unconstrained mi nimum variance point that corresponds to a short position in the unindexed pension. As the indifference curves in figure 2 indicate, whenever $\sigma_{b b}^{2}>\sigma_{u b}^{2}$ the optimum pension will never be invested completely in the security that provides the greatest indexing. This is obvious when the minimm variance real return requires only partial indexing $\left(\sigma^{2} u b<\sigma^{2} b b\right)$; only the portion of the $b \bar{U}$ locus between $\hat{U}$ and $\bar{U}$ is efficient since a more completely indexed pension would have both a lower expected return and greater variance. But even when the unconstructed minimum variance pension is invested in bills only $\left(\sigma_{\mathrm{ub}}^{2}=\sigma_{\mathrm{bb}}^{2}\right)$, the optimum pension is at least partly unindexed because at point $b$ a small increase in

1 If the constraint that prohibits short positions were relaxed, the minimum variance pension might involve a negative amount of the unindexed pension. Bodie's calculation that the minimum variance portfolio contains only bills is actually a constrained minimu with the short sale of bonds prohibited. Bodie's calculation also assumes $\mu_{\mathrm{b}}=0$. 
Figure 2

Optimal Pension Indexing when Bills are Risky

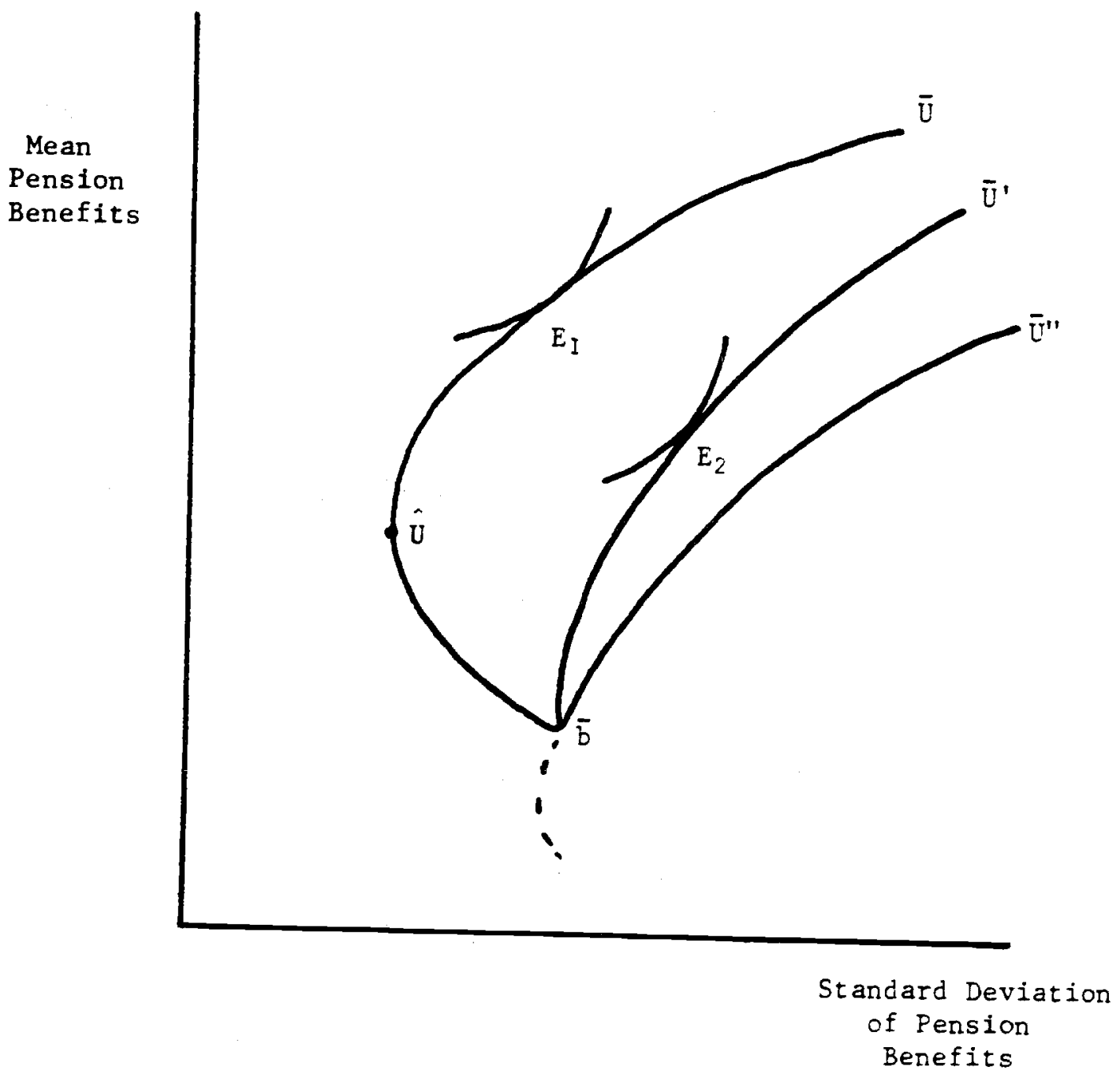


yield can be obtained with essentially no increase in risk. ${ }^{1}$ Only in the case where the bills-only pension represents a constrained minimum variance $\left(\sigma^{2} \mathrm{ab}>\sigma_{\mathrm{bb}}^{2}\right)$ might an indifference curve be tangent to the opportunity locus at $\bar{b}$. Of course, in all three cases individuals with low enough risk aversion will prefer to have no indexing at all.

These ideas can again be made more precise by considering the special case of a constant absolute risk aversion utility function. It follows from equations 1.1 and 1.2 that

$$
\begin{aligned}
E[V(P)]= & E\left[-\frac{1}{\alpha} e^{-\alpha P}\right] \\
= & E\left[-\frac{1}{\alpha} e^{-\alpha\left[(C-U)\left(1+r_{b}\right)+U\left(1+r_{u}\right)\right]}\right. \\
= & -\frac{1}{\alpha} \exp \left\{-\alpha\left[(C-U)\left(1+\mu_{b}\right)+U\left(1+\mu_{B}\right]\right.\right. \\
& \left.+\frac{1}{2} \alpha^{2}\left[(C-U)^{2} \sigma^{2} b b+U^{2} \sigma^{2} u U+2 U(C-U) \sigma_{u b}^{2}\right]\right\}
\end{aligned}
$$

Maximizing $E[V(P)]$ with respect to $U$ implies:

$$
U^{*}=\frac{\mu_{a}-\mu_{b}+\alpha C\left[\sigma_{b b}^{2}-\sigma_{u b}^{2}\right\rfloor}{\alpha\left\lfloor\sigma_{U U}^{2}+\sigma_{b b}^{2}-2 \sigma_{U b}^{2}\right\rfloor}
$$

Since the value of $U$ that minimizes the real variance is $\hat{U}=$ $c\left(\sigma_{b b}^{2}-\sigma_{u b}^{2}\right) /\left(\sigma^{2} u u+\sigma_{b b}^{2}-2 \sigma^{2} u b\right)$, it is clear from equation 1.7 that the

I At $U=0, \mathrm{~d} \sigma / \mathrm{d} \mu=0$. To see this, note that the variance of the pension is $\sigma^{2}=\left[(C-U)^{2} \sigma_{b b}^{2}+U_{u u}^{2}+2 U(C-U) \sigma^{2}{ }_{u b}\right]$ and therefore $d \sigma^{2} / d U=2\left[-(C-U) \sigma^{2} b b\right.$ $+U \sigma_{u u}^{2}+(C-2 U) \sigma_{u b}^{2} \mathrm{l}$. When $\sigma_{\mathrm{ub}}^{2}=\sigma_{\mathrm{bb}}^{2}, \mathrm{~d} \sigma^{2} / \mathrm{dU}=0$ at $\mathrm{U}=0$. Since $d \mu / d U=\left(\mu_{\mathrm{u}}-\mu_{\mathrm{b}}\right)>0, d \sigma / d \mu=0$. 
optimal pension will always have less bills (and therefore greater variance) than the minimum variance investment. When variations in the real yields on bills and the unindexed pension are negatively correlated $\left(\sigma^{2} \mathrm{ub}<0\right)$, the minimum variance $\hat{U}>0$ and therefore $U^{*}>0$. Moreover, for a sufficiently low degree of risk aversion, $U^{*}>A$ and the pension is completely unindexed. Similarly, if $\sigma_{\mathrm{bb}}^{2}=\sigma_{\mathrm{ub}}^{2}, \hat{U}=0$ but $U^{*}>0$ and, for low enough $a, U^{*}>C$. Thus even when the unconstrained minimum variance pension requires investing in bills only, the optimal pension will be partly unindexed and may be completely unindexed. Only when $\sigma_{\mathrm{bb}}^{2}<\sigma_{\mathrm{ub}}^{2}$ by enough to offset the yield differential $\left(\mu_{B}-\mu_{b}\right)$ will the pension be invested exclusively in bills but, in that case also, the bills only portfolio does not achieve the minimum variance.

The results of this section can be summarized briefly. Even when a perfectly indexed pension can be obtained by investing pension funds in money market instruments ("bills"), individuals will always prefer a less than completel $\because$ indexed pension. When bills are a risky asset, the minimum variance pension may be achieved by investing in bills only or by a partly indexed pension, depending on the regression coefficient between the unindexed pension yield and the bill yield. Individuals will, however, always prefer a pension that has more real risk than the minimum variance pension. In both cases, the individual who has a sufficiently low degree of risk aversion will want a pension that is invested exclusively in the higher yielding asset and that makes no attempt to reduce the risk of inflation.

\section{Pension Indexing with Riskless Social Security}

As Paul Samuelson (1958) has shown, a pay-as-you-go Social Security pension pays a real return on tax "contributions" equal to the real growth rate 
of labor income. This is easily shown in the context of the present two-period model. Assume that there are $\mathrm{N}_{1}$ workers in the current generation (denoted by the subscript 1) and that each worker earns a real wage of $w_{1}$. If the Social Security program imposes a tax at rate $t$, the total contribution of these workers is $T_{1}=t w_{1} N_{1}$. These funds are immediately paid out as benefits to the current retirees (i.e., the previous generation of workers). The next generation of $\mathrm{N}_{2}$ workers will earn $\mathrm{w}_{2} \mathrm{~N}_{2}$ and pay a total tax of $\mathrm{T}_{2}=t \mathrm{w}_{2} \mathrm{~N}_{2}$ if the tax rate remains unchanged. These tax revenues will then be paid out as Social Security benefits to the current employees, $B_{1}=t w_{2} N_{2}$.

The relation between the taxes paid by the current generation of workers $\left(T_{1}\right)$ and the benefits that they subsequently receive $\left(B_{1}\right)$ is thus:

$$
\begin{aligned}
\frac{\mathrm{B}_{1}}{\mathrm{~T}_{1}}=\frac{\mathrm{t} \mathrm{w}_{2} \mathrm{~N}_{2}}{t \mathrm{w}_{1} \mathrm{~N}_{1}} & =(1+\gamma)(1+\mathrm{n}) \\
& =(1+\mathrm{g})
\end{aligned}
$$

where $\gamma$ is the growth rate of real wages per employee, $n$ is the growth rate of the labor force, and $g$ is the growth rate of total labor income. Thus, even though Social Security contributions are not invested, participants earn a real return on their contributions in a growing economy. In the U.S. economy during the past 30 years, total employee compensation has grown at an average annual rate of about 3 percent. 1

The important feature about the Social Security program in the present context is that its pay-as-you-go character makes it automatically indexed. The

1 The rate of return on Social Security contributions during this period was substantially greater because the tax rate $(t)$ was increased substantially (from 0.020 in 1950 to 0.133 in 1981). Social Security taxes are also levied only on a portion of payroll income and not on the entire employee compensation. 
real tax revenue available to pay benefits may vary with productivity and with changes in population growth and labor force participation, but it does not depend on the price level. As a result, the United States and other countries with pay-as-you-go Social Security pensions promise benefits that are fully indexed to inflation. ${ }^{1}$ In this paper, I shall take the pay-as-you-go (i.e., unfunded) character of Social Security as given ${ }^{2}$ and ask how the existence of such Social Secuity benefits influence the optimal indexing of private pensions. To begin, I shall assume that there is no uncertainty about the rate of growth of earnings $(g)$ and therefore that Social Security can provide an indexed pension with a fixed rate of return, g. I shall examine the optimal mix of Social Security and a private pension in this case and then the effect of an arbitrarily fixed amount of Social Security on the optimal indexing of the private pension. The fourth section extends the analysis to the more general situation in which uncertainty about real growth of earnings implies uncertainty about the real return on Social Security.

The simplest case to consider is the one in which bills provide a perfect store of value with no uncertainty and a zero real return. Social Security with expected return $g$ and no uncertainty then clearly dominates any investment in bills. The individual prefers a combination of Social Security and a completely unindexed private pension, with the preferred combination reflecting the

1 Before 1972, the U.S. Social Security system was not formally indexed. The law was changed occasionally to adjust the benefits of retirees but real benefits did fluctuate around a generally constant ratio of benefits to real wages. serious and persistent problem $1960^{\prime}$ s that inflation began to appear as a 2 The alternative would be to accumlate a Social Security fund and use its earnings to pay benefits. The working generation could guarantee the real value of benefits to retirees, varying the tax rate to obtain the necessary funds. 
individual's risk aversion, the expected returns on an unindexed pension and on Social Security and the variance of the real yield on the unindexed pension. It is worth emphasizing that in this important case the optimal private pension is completely unindexed. Private pensions may be indexed only because of departures from the assumptions of this case: uncertain returns on bills or on Social Security or a suboptimal amount of Social Security.

This case is illustrated in figure 3. Point $\bar{U}$ corresponds to a private pension invested only in bonds and no Social Security. Point $\bar{b}$ corresponds to a fully indexed private pension invested only in bills and no Social Security. Point $\bar{S}$ corresponds to Social Security only, with no private pension. It is clear that point $\overline{\mathrm{S}}$ dominates point $\overline{\mathrm{b}}$ and that, while any point in the triangle connecting points $\bar{b}, \bar{S}$ and $\bar{U}$ is feasible, only points on the $\bar{S} \bar{U}$ line are efficient. The indifference curve is drawn so that the optimal pension (at $E_{l}$ ) is one-half Social Security and one-half an unindexed private pension. For an individual with a constant absolute risk aversion utility function, the optimal amount of the unindexed private pension is

$$
U^{*}=\frac{\mu_{u}-\mu_{s}}{\alpha \sigma_{u u}^{2}}
$$

where $\mu_{S}$ is the yield on Social Security tax contributions. The optimal amount to be contributed to Social Security is then $C-U^{*} .^{1}$

1 I continue to assume that the total amount of retirement savings is fixed and divided between Social Security and the private pension. 
Figure 3

Optimal Pension Indexing with Social Security and Riskless Bills

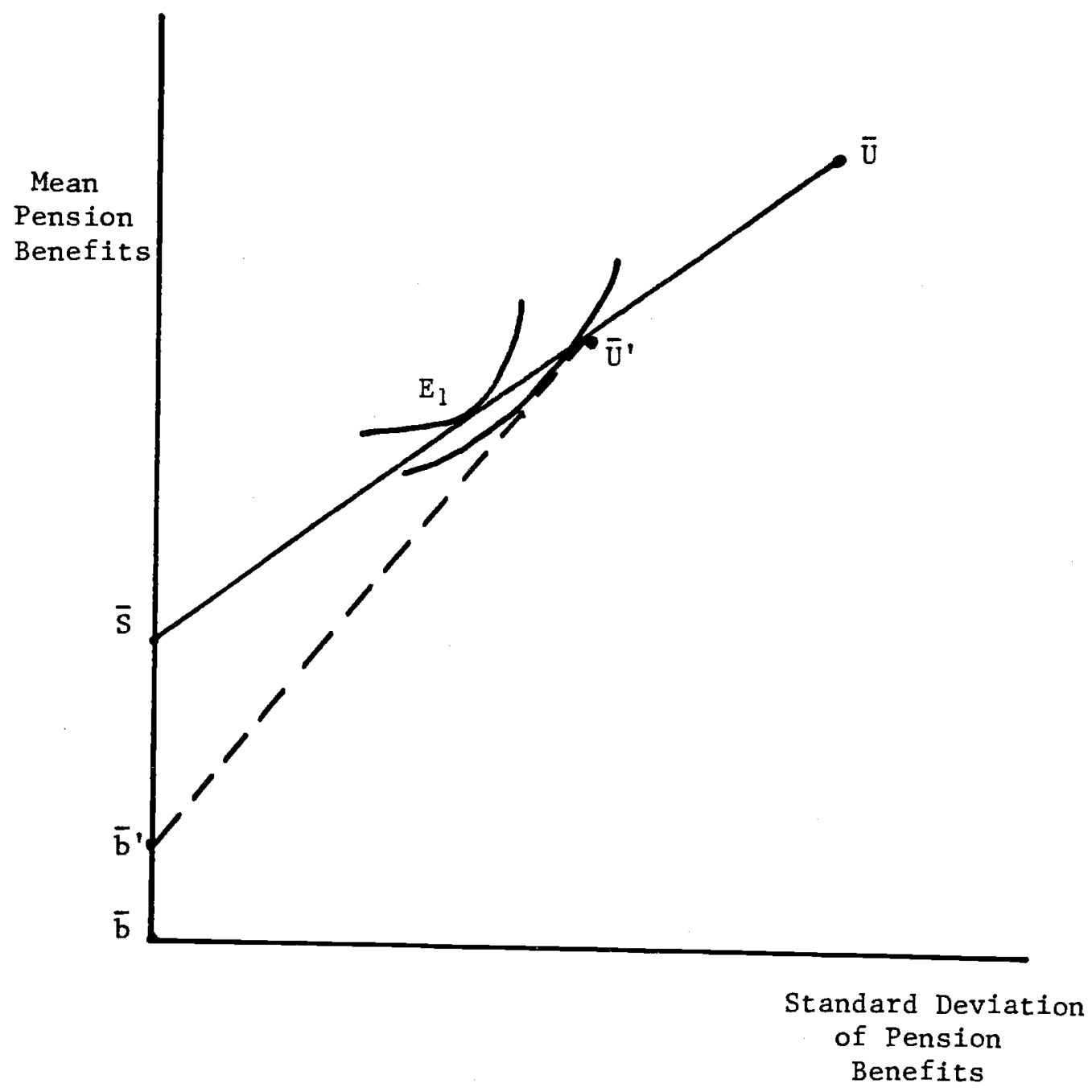


Before leaving this case, it is interesting to note the effect of inflation uncertainty on the optimal amount of Social Security. With constant absolute risk aversion, the effect is unambiguous. An increase in inflation uncertainty implies a higher value of $a_{u u}^{2}$ and therefore depresses $U^{*}$ in equation 2.2. More inflation uncertainty implies greater reliance on unfunded Social Security and less on the funded private pension. Note that this is true even though a completely indexed private pension could be achieved by investing the pension assets in bills. With a more general utility function the effect of an increase in inflation uncertainty is formally ambiguous but is likely to increase reliance on Social Security. When inflation uncertainty increases, the tradeoff between risk and return becomes less favorable to bonds while the amount of uncertainty at the initial level of Social Security becomes greater. With greater initial levels of risk and a lower cost of reducing risk, the individual is likely to want to reduce risk by increasing reliance on social Security $\cdot^{1}$ Until now, the analysis has assumed that the amount of Social Security is set optimally. If the size of the Social Security pension is instead set exogenously at a level that is less than optimal, individuals may

1 This substitution of a low yield unfunded Social Security pension for real capital formation in a funded private pension is another of the adverse consequences of increased inflation uncertainty.

Someone who was trying to develop a positive theory of the growth of Social Security benefits might note that optimal behavior required a rise in relative benefits as inflation and inflation uncertainty increased and that this is indeed what has happened in recent years. A worker with median earnings who retired at age 65 received benefits equal to about one-third of peak earnings until 1972. A change in the benefit formula then caused the ratio to rise rapidly to more than 50 percent (in 1980) with an implied steady state value of more than 40 percent. A more historically minded student of Social Security might explain the unprecedented rise by the electoral politics of 1972 and the unintended effects of inappropriate indexing formlae. 
want to ir.jex partially their private pension. In figure 3 , the kinked line connecting points $\bar{b}^{\prime}$ and $\bar{U}^{\prime}$ represents the efficient frontier when the amount of the Social Security contribution is constrained to equal one-third of $C$. If the private pension (i.e., the amount C-S) is completely indexed, the value of the pension will be $\mathrm{C}\left(1+\mu_{\mathrm{s}} / 3\right)$. This is shown as point $\bar{b}^{\prime}$, one third of the way between $\bar{b}$ and $\bar{S}$. If the private pension is completely unindexed, the expected value of the pension is $(C-S)\left(1+\mu_{u}\right)+S\left(1+\mu_{S}\right)$ and its standard deviation is (C-S) $\sigma_{\text {uu }}$. This is shown as point $\bar{U}^{\prime}$. If the indifference curve is tangent to the line segment $\bar{b}^{\prime} \bar{U}^{\prime}$, the optimal private pension is partially indexed. But since the segment $\bar{b} \cdot \bar{U} '$ is steeper than $\overline{S U}$, the indifference curve need not be tangent between $\bar{b}^{\prime}$ and $\bar{U}^{\prime}$. In figure 3 , the relevant indifference curve touches the line at the kink point $\bar{U}$ 'where the private portfolio is not indexed at all. Although it may seem surprising that a reduction in the indexed Social Security pension does not always induce an increased indexation of the private pension, this merely reflects the fact that the private fully indexed pension has a lower yield than the Social Security pension.

If there is no riskless private asset, the analysis of the optimal mix of Social Security and the private pension assets and of the impact of changes in the exogenously set level of Social security is more complex. In figure 4 , the $\bar{b} \bar{U}$ curve represents the purely private pension with different combinations of bills and an indexed pensions. If the value of a pure social Security pension corresponds to point $\overline{\mathrm{S}}_{1}$, any point on any line between $\bar{S}_{1}$ and the $\bar{b} \bar{U}$ locus is feasible. However, only the points on $\bar{S}_{1} \bar{U}$ are efficient; all other feasible points have lower means for the same variance. But if the value of a pure Social Security pension corresponds to point $\overline{\mathrm{S}}_{2}$ the line connecting $\bar{S}_{2}$ and $\bar{U}$ (not drawn) is inefficient. The efficient set of feasible pensions 
Figure 4

Optimal Pension Indexing with Social Security and Risky Bills

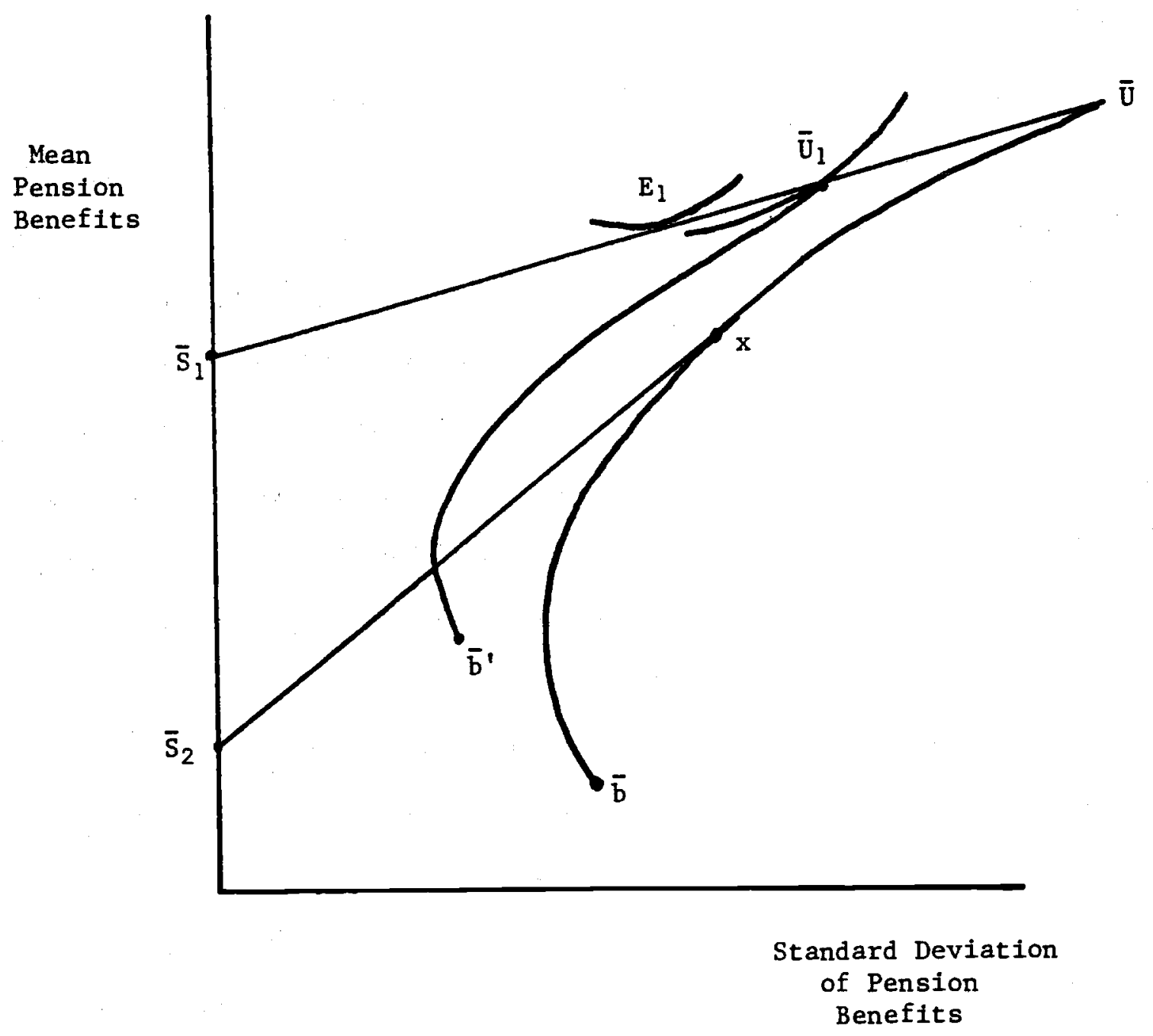


correspond to combinations of Social Security and a partly indexed pension (if the optimum occurs on the straight segment $\left.\bar{S}_{2} X\right)$ or to a partly indexed pension with no Social Security if the optimam lies on the segment $X \bar{U}$ of the private pension curve. In either case, the private pension will not be invested only in bills and will in fact contain less in bills than the mi nimum variance pension fund. Of course, with low risk aversion the indifference curves may not be tangent at any feasible point, implying that the optimum is a completely unindexed private pension.

Constraining the amount of Social Security to be less than the optimal amount has the same general effect when bills are risky as it does when they provide a perfect index asset. The optimal pensions may involve increased indexing or, if the individual is not very risk averse, no change in the original degree of indexing. In particular, even with the amount of social security reduced, a completely unindexed pension may be optimal. This is illustrated in figure 4.

In the case in which the value of the pure Social Security pension would be $\bar{S}_{1}$, the optimum pension (at $E_{1}$ ) consists of an equal mix of Social Security and the completely unindexed pension invested in bonds. Now constrain the amount of Social Security to be one-third of the total pension contribution: $S=C / 3$. This implies that if the private pension is completely unindexed, the total expected pension value is $S\left(1+\mu_{S}\right)+U\left(1+\mu_{u}\right)=\left(1+\mu_{s} / 3+2 \mu_{u} / 3\right) C$ and the corresponding standard deviation is $2 \mathrm{C} \sigma_{u u} / 3$; this combination is shown at point $\bar{U}^{\prime}$. Similarly, if the private part of the pension is completely indexed, the mean and standard deviation of the total pension value is shown at point $\bar{b}^{\prime}$. The new opportunity locus is constructed in this way for all points between $\bar{b}^{\prime}$ and $\bar{U}^{\prime}$. The new optimum private pensions could involve partial 
indexing (i.e., correspond to some point on the $\bar{b}^{\prime} \bar{U}^{\prime}$ locus), but since the slope of the new locus is steeper than the slope of the $\bar{S} \bar{U}$ line, the optimum may occur at a corner solution at point $\bar{U}$ ' as shown in figure 4.

\section{Optimal Indexing with Uncertain Social Security}

Although unexpected changes in the price level do not alter the real value of a Social Security pension, unexpected changes in the growth of the real wage rate or in the growth of the labor force are a source of potential uncertainty in Social Security benefits that was ignored in the previous section. ${ }^{1}$ The present section assumes that Social Security provides an uncertain pension. Because the general case in which both bills and bonds are also uncertain assets is complex to analyze and not particularly informative, I focus on the case in which bills provide a perfect index asset with zero real return and no variance. One example of this situation is shown in figure 5. As usual, point $\bar{b}$ represents a completely indexed private pension, point $\bar{U}$ a completely unindexed private pension, and point $\bar{S}$ no private pension but reliance only on Social Security. The shape of the $\bar{S} \bar{U}$ curve, particularly the fact that the minimum variance point does not correspond to $\overline{\mathrm{S}}$, implies that variations in the yield on Social Security and on bonds are either independent, negatively correlated or correlated in a weak positive way. ${ }^{2}$ Since this restriction seems to me to be rather mild, I shall not deal explicitly with the alternative case; the results are easily derived by a simple modification of figure 5 .

Points along the $\bar{S} \bar{U}$ curve represent combinations of Social Security and a completely unindexed private pension. Points on the $\bar{b} \tilde{U}$ line represent

1 I say "potential" uncertainty because the Social Security program may guarantee real benefits and allow the tax rate on employees to vary. The present U.S. legislative debate about the choice between raising taxes and reducing benefits is testing whether the "uncertainty" is "potential" or "actual".

2 The formal condition is that the regression of the unindexed pension yield on the Social security yield be less than one. 
Figure 5

Optimal Pension Indexing with Uncertain Social Security

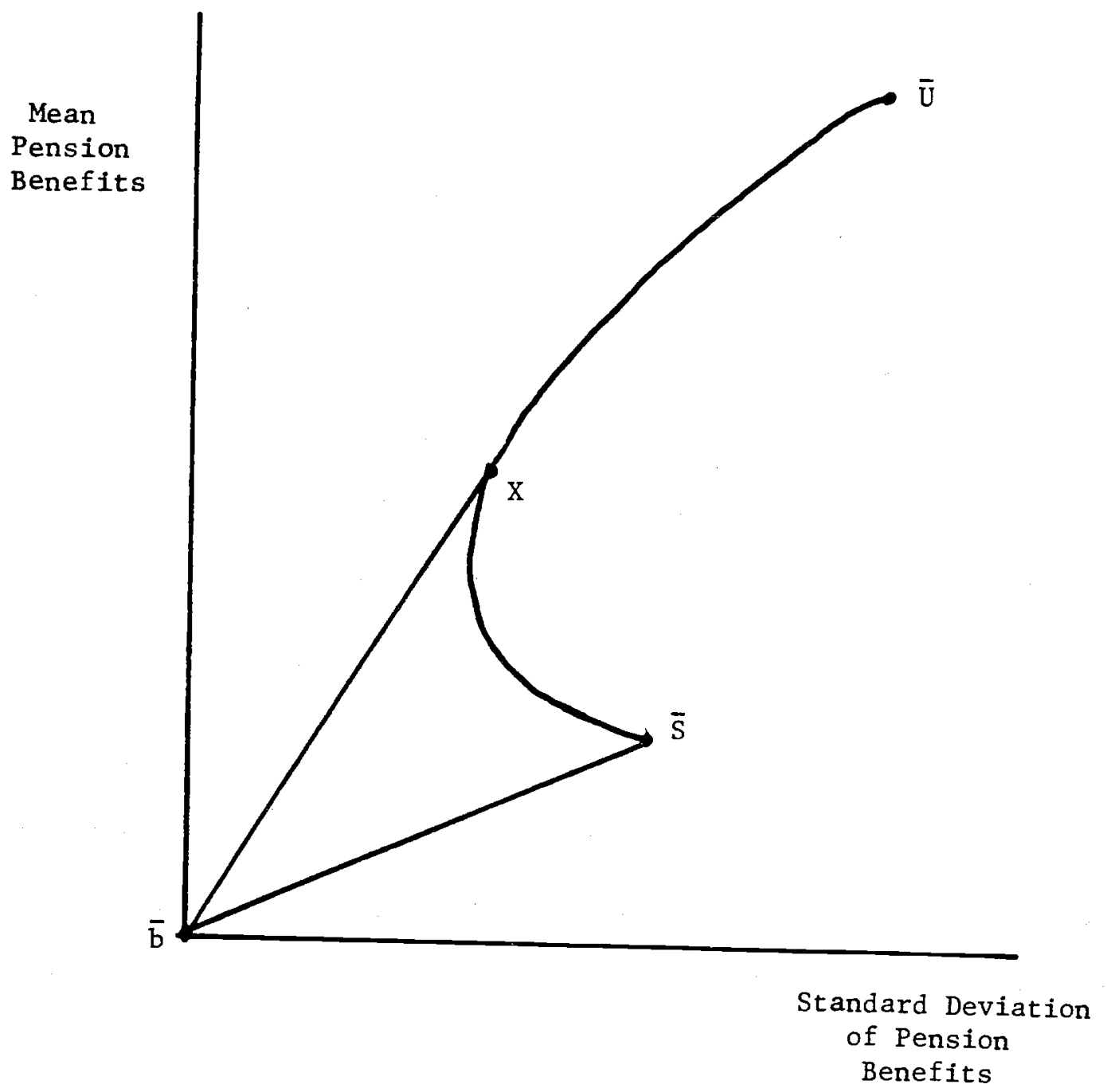


combinations of Social Security and a completely indexed private pension. Fianlly, points on the line between $\bar{b}$ and the point of tangency with the $\overline{U S}$ curve (at $X$ ) represent combinations of Social Security and a partially indexed private plan.

Since the efficient frontier consists of the line bX and the segment of the curve between $X$ and $U$, several possible pension arrangements can immidiately be excluded as never optimal for any utility function. First, it is never optimal to rely exclusively on either social security (point $\bar{S}$ ) or on a completely indexed private pension (point $\bar{b}$ ). Further, it is never optimal to use a combination of just Social Security and a fully indexed private pension (points on line $\overline{\mathrm{bS}}$ ) since a higher mean can be obtained with the same variance by using a less than fully indexed private pension.

An individual with sufficiently low risk aversion will prefer to have only a private pension and one that is not indexed at all. For such an individual, there will be no tangency on the $\bar{b} \times \bar{U}$ locus but the highest feasible indifference curve will touch point $\vec{U}$. With more risk aversion, a tangency will occur along the $\bar{X}$ curve where the individual has a combination of Social Security and a completely unindexed private pension. Only with sufficiently great risk aversion will the indifference curve tangency occur along the $\overline{\mathrm{bX}}$ line where the individual combines Social Security with a partially indexed private pension.

Figure 6 presents a modified form of figure 5 in which no ray from the origin (i.e., from point $\bar{b}$ ) is tangent to the curve generated by combinations of Social Security and the unindexed private pension. Economically, this occurs 
Figure 6

Optimal Pension Indexing with Uncertain Social Security

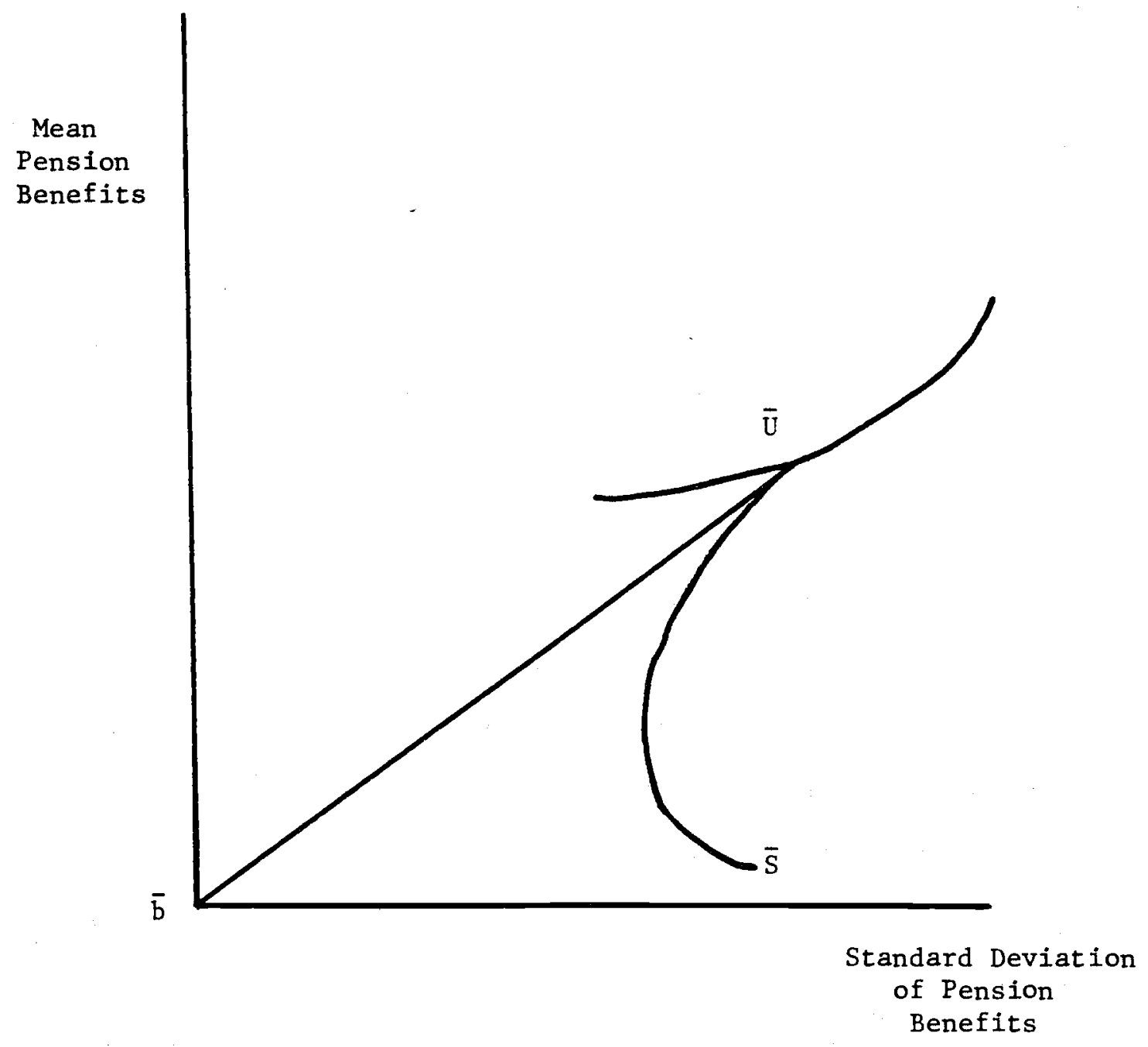


when tre yield on an unindexed pension is sufficiently high relative to its risk. In this case, the efficient set is just the straight line $\bar{b} \bar{U}$. It is never cptimal in this case to have any Social Security and the optimal private pension is either unindexed (as shown by the highest feasible indifference curve touching the $\bar{b} \bar{U}$ line at $\bar{U}$ ) or, for a more risk averse individual, by a partly indexed private pension (with the indifference curve tangent on the $\bar{b} \bar{U}$ line).

\section{Conclusion}

The analysis in this paper was motivated by the apparent puzzle that, despite substantial uncertainty about future inflation rates, private pensions are alzost universally unindexed. Moreover, although a variable annuity invested in short-term money market instruments provides a good inflation hedge, almost all private pensions provide a fixed annuity.

The results of the analysis indicate that the existence of unindexed pensions and fixed annuities is not at all surprising. Even without Social Security, it may be optimal to have a completely unindexed private pension and it is generally not optimal to have a completely indexed pension.

The availability of an optimal (or greater than optimal) amount of Social Security generally reduces the desired degree of indexing and, under a variety of conditions, makes it optimal to have no indexing at all in the private pension.

Because unexpected changes in the price level do not alter the value of Social Security pensions, the existence of inflation uncertainty makes a Social Security pension optimal when it would not otherwise be and an increase in inflation uncertainty is likely to increase the optimal reliance on Social 
Security. But despite these conclusions, the analysis shows that including some Social Security in an overall pension program is necessarily optinal only when both money market instruments and Social Security have rates of returr that are known with certainty. When the real yield on money market instruments is uncertain, the optimal pension arrangement may be a partially indexed private pension even though Social Security is risk-free and has a return that is higher than the expected rate on the money market instruments. Similarly, when Social Security is risky, the optimal arrangement may be to exclude Social Security and to use a partially indexed private pension. In all cases, an individual who has a low enough degree of risk aversion will prefer no Social Security and a completely unindexed private pension. 


\section{Bibliography}

Arrow, Kenneth (1971) Essays in The Theory of Risk Bearing, Chicago: Marhham Publishing Co., 1971.

Bodie, Zvi, (1979), "Inflation Risk and Capital Market Equilibrium," NBEF. Working Paper No. 373.

Bodie, Zvi (1980a) "An Innovation for Stable Real Retirement Income," Journal of Portfolio Management, Fall.

Bodie, Zvi (1980b), "Purchasing-Power Annuities: Financial Innovation for Stable Real Retirement Income in an Inflationary Environment," NBER Working Paper No. 442.

Bodie, Zvi (1981), "Investment Strategy in an Inflationary Environment," NBER Working Paper No. 701, forthcoming in B.M. Friedman (ed.), The Changing Roles of Debt and Equity in Financing U.S. Capital Formation.

Bulow, Jeremy (1981) "Tax Aspects of Corporate Pension Funding," paper given at the NBER Conference on Private and Public Pensions, July 13-14, 1981.

Feldstein, Martin (1980a) "Inflation and the Stock Market," American Economic Review 70, 839-47.

, (1980b) "Inflation, Tax Rules and the Stock Market," Journal of Monetary Economics 6, 309-31.

Feldstein, Martin (1981) "Private Pensions as Corporate Debt", NBER Working Paper No. 703, forthcoming in B.M. Friedman, (ed.), The Changing Roles of Debt and Equity in Financing U.S. Capital Formation.

Hendershott, Patric and S.C. Hu (1979) "Inflation and the Benefits of OwnerOccupied Housing, NBER Working Paper No. 383.

Miller, Merton H. and Myron Scholes, "Pension Funding and Corporate Valuation," University of Chicago, 1981.

Mishkin, Frederic S. (1981) "Monetary Policy and Short-Term Interest Rates: An Efficient Markets-Rational Expectations Approach," IBER Working Paper No. 693 .

Pesando, James (1981), "Eployee Valuation of Pension Claims and the Inpact of Indexing Initiatives," paper given at the NBER Conference on Private and Public Pensions, July 13-14, 1981. 
Summers, Lawrence (1981a) "Inflation, the Stock Market, and Owner Occupied Housing," American Economic Review 71, 429-34.

(1981b) "The Non-Adjustment of Nominal Interest Rates: A Study of the Fisher Effect," NBER Conference Paper, forthcoming.

Samuelson, Paul A. (1958) "An Exact Consumption-Loan Model of Interest With or Without the Social Contrivance of Money," Journal of Political Economy 66
467-82.

Tobin, James E. (1958) "Liquidity Preference as Behavior Toward Risk," Review of Economic Studies 23, 65-86. 